\title{
Computer Based Test (CBT) System for Student Academic Examination
}

\author{
Agnes Manurung ${ }^{1}$, Amalia Fildzah $^{2}$, Juniastel Rajagukguk ${ }^{3}$ \\ \{ agnesmanurung27, amaliafildzah502@gmail.com, juniastel@unimed.ac.id \} \\ Department of Physics, Universitas Negeri Medan, Jalan Willem Iskandar Pasar V, Medan Estate \\ 20221, Indonesia ${ }^{1,2,3}$
}

\begin{abstract}
Computer based test (CBT) becomes more pervasive in the last few decades, there is growing need for educators to consider modes of assessment because there are many advantages. CBT is an effective solution for mass education evaluation, so that CBT is very necessary applied especially in evaluation and assessment for students. The purpose of this research is to design a system for student academic examination based on computer based test (CBT). The system is designed to facilitate the examnination processes and manage challenges surrounding the conduct of examination, autosubmission, auto-marking and examinaton result report generation. The kind of this research is part of research and development $(R \& D)$ research. Model design is adopted from Thiagaraja, which have four-D model: (1) define, (2) design, (3) development, (4) disseminate. This research was executed until the limited trial of design model because the lack of the time of this study. Define was analysed student's need, the goal, and the CBT's concept. Design was choosed the CBT's software, software that used in this study was learning management system (LMS) Moodle. The goal of this study is create CBT system for student examination and showed the effectivity of the system.
\end{abstract}

Keywords: CBT, Student's Examination, Moodle

\section{Introduction}

The world is now in the fourth generation of industry revolutionaries (the 4.0 industrial revolution). The development of this fourth generation of revolution has not come off the influence of education. The education in Indonesia is also capable to face 4.0 revolution challenges. One of the attempts to be done is to connect between education and the development of technology. The use of computers had become very popular in education department in the last few decade. Computers are used in education from presenting the lesson to student examination. Computer-based testing (CBT) has emerged as one of the recent "innovative" approaches to assessments most pursued by states. CBT is lauded as the answer to having cheaper and speedier test delivery for state and district-wide asessments (Thurlow, et al., 2010). Virtually errorless high speed data processing feature has made computers accepted assesment tools in education (Akdemir, et al., 2008). Testing based paper and pencil had become the old way and and left behind and start to use computers as a tools for saving, access, and process the test (Martin, 2008). This assessment known as computer based test (CBT). CBT is the efective solution for a evaluation change in education (Piech \& Gregg, 2018) 
CBT has many advantages, so made the CBT getting noticed and become interested to use in evaluation and education in all over the world. The interest in developing and using computer-based test (CBT) in assessment in schools and educational institutions has heightened in recent years. CBT considered as the effective and up to date way of giving an assessment (Shilova, et al., 2014). The benefit ranged from the automation of marking and subsequent reduction in marking workload to oppurtunity to provide students with immediate feedback on their performance. The use of CBT is an attempt to overcome these limitations and go some way to make course and assessments more interesting and useful processes for both teachers and students (Hurley, 2017). The use of CBT can improve the efficiency and profitability of academic institutions. It reduces the cost of stationeries and labor involved in conducting examination manually. This work can be improved through the introduction of the forms of questions types such as theory based and diagrammatic questions to make the test questions more diverse (Kuyoro, 2016)

CBT is the effective transformation that can be used for the educator nowdays. CBT offers the higher potential and the value either than paper based test (PBT) (Haryanto, 2017). A teacher slowly should exploited computer as way to give an assessment to the students. The reason that should using CBT because CBT has many benefit that everyone could get either than using PBT. Some of the drawback includes malpractices, waiting for results, wastage of resource such as pen, paper, etc., collecting answer sheet, mistake occurs during evaluation etc., (Singh et al, 2016).

In this paper, software that use for the CBT is learning management system Moodle. Moodle is a free learning management system that allowed you to create powerful, flexible and enganging online learning experiences. The word moodle was originally an acronym for Modular-Object-Oriented Dynamic Learning Environment, which is mostly useful to to programmers and education theorists (William, 2011). There have been a number focusing on the development of automated examination systems and electroning learning information systems. Al-Qdah, et al (2003) survey about their experiences with both exams, the students indicated to prefer certain aspects of online exam, such as automatic results and feedback. Singh, et al (2016) a secure online examination system without paper has been designed and proposed for examinations to be conducted at different places. By CBT, resources like time, energy to evaluate every single answer sheet and the need to use paper is reduced. Arachchi, et al (2014) computer based testing is much better and have proved it is more successfull than the paper based testing due to the following advantages. Al Saleem (2016) computer based testing offers a lot of options that have implications for test reliability and length, security, cost and maintanance, and other program needs for test administration that are not possible with traditional paper-and-pencil based test. The goal of this research is to create and to know how to make the CBT system for student examination and showed the effectivity of the sytem.

\section{Method}

This kind of research is part of research and development research. This research was conducted with some steps, that is define consist of front-end analysis, learner analysis, task analysis, concept analysis, specifying instructional analysis. Design consist of criterion test construction, media selection, format selection, initial design. Development consist of expert appraisal and development testing and disseminate. But this study was limited to the second stage of design. The instrument used to collect the data was (1) CBT that has been developed 
with moodle software, (2) instrument test, (3) CBT validation, (4) test validation, (5) questionnaire for students, (6) the list of interview for students. The techniques to collect the data was observation, questionnaire, and interview. The validation sheets was addressed to the judgement experts to know the effectiveness of CBT. The stages of design showed Figure 1:

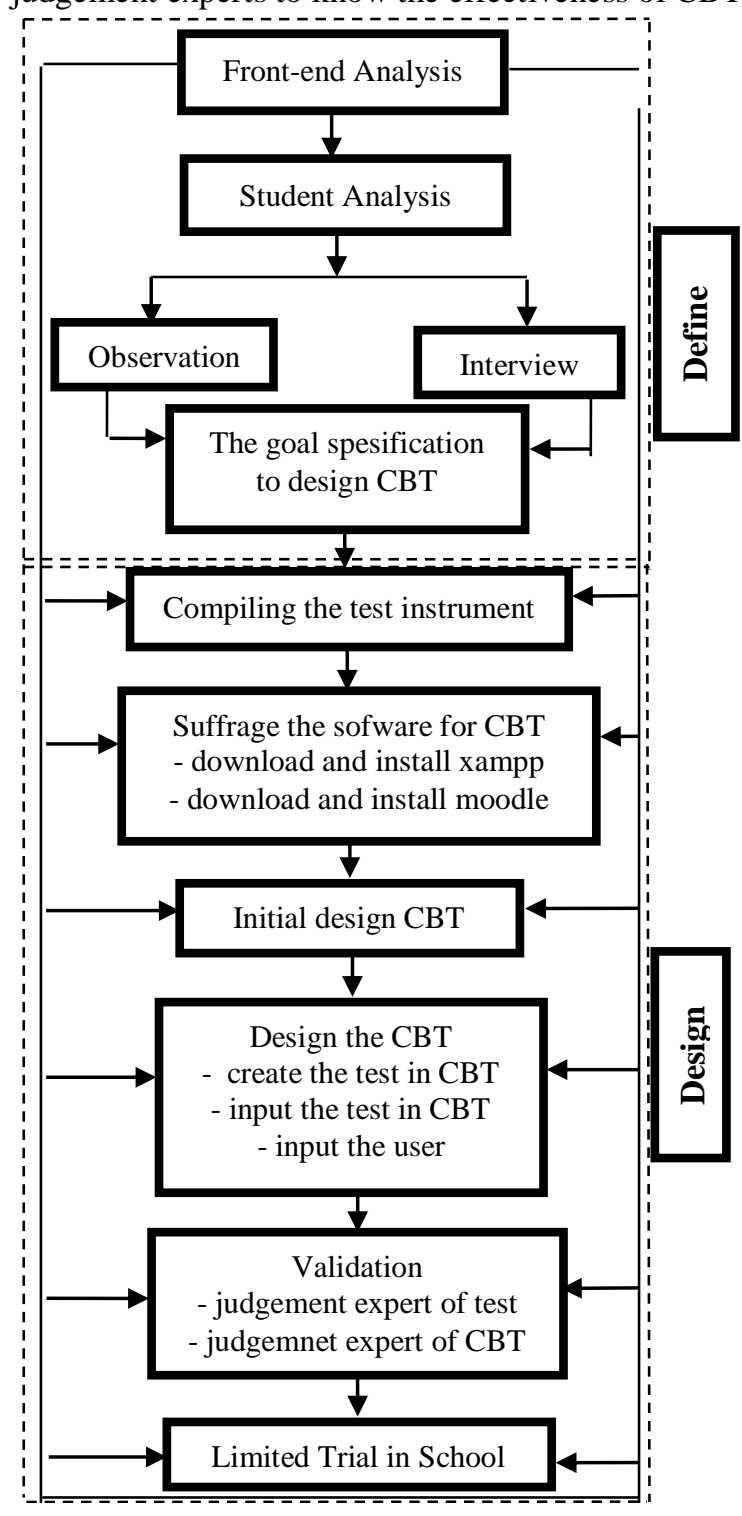

Figure 1: The Stages of Design 


\subsection{Data Analysis}

The validation sheets was addressed to the judgement experts to know the effectiveness of CBT. The validation sheets using Guttman scale with 2 alternative yes or no answers. Mark from the judgement experts answers could be seen on the Table 1.

Table 1: CBT Validation Criteria

\begin{tabular}{|c|c|}
\hline Answer & Score \\
\hline Yes & 1 \\
\hline No & 0 \\
\hline
\end{tabular}

After the data was obtained, then analyzed the data. Data was analyzed by a statistical descriptive system. The next stage to analyze the data was:

(1) The questionnaire that has been filled by the respondents, examined the complementary items taht are subsequently assembled.

(2) Quantified the answer to each question by giving the score.

(3) Made the data tabulation

(4) Calculated the percentage of each variable.

(5) Made the range from the score that had been gotten.

\subsection{Conceptual Design}

The conceptual design of the CBT system was carried out the activity diagram, the data flow diagram, the use diagram and entity-relationship diagram.

\subsubsection{Activity Diagram}

Activity diagrams can be used to describe the operational step by step workflows of components in a system. An activity diagram show the overall flow of control. However, figure 2 presents the activity diagram for the CBT system develop.

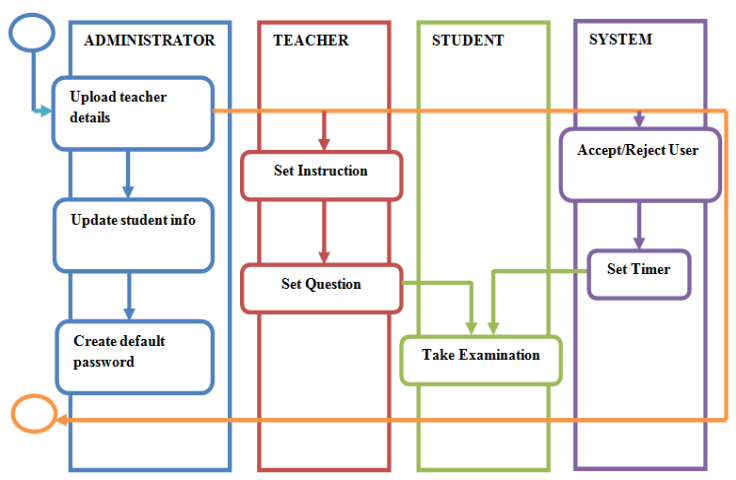

Figure 3: Activity Diagram for the CBT Sytem 


\subsubsection{Data Flow Diagram}

The data flow diagram presents the functions performed by the CBT system. Figure 3 below shows a relationships among the entities in CBT system. The entity 'student' can take examination after they gains access to the system. The entity 'teacher' can upload questions to be answered by student into the CBT database using any preferred question format, set the examination instructions and configure the correct options or set of options for the questions. The entity 'administrator' is saddled with the responsibility of inserting students, teacher and setting the default password for the users of the system. The entity 'server' is responsible for authenticating the users of the system and also provides the timing functionality for the examination. The system logs off a student upon expiration of duration for the examination.

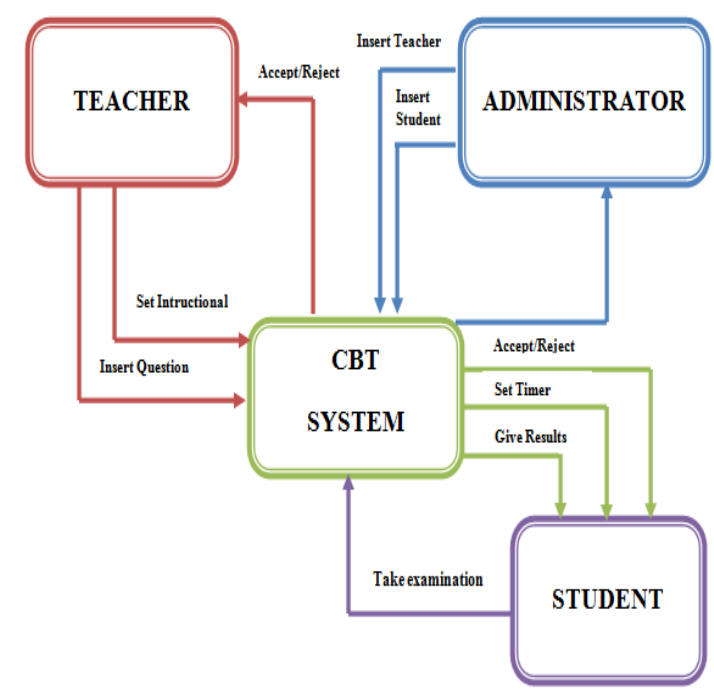

\subsubsection{Cbt Diagram For User}

Use cases diagram for each entity present in the CBT system below. These iclude use cases diagram for the administrator, teacher, system and student. The use cases diagram for the administrator is presented inFiguere 4. It shows the activities that are required of the administrator including the upload of techer's details and creation of default password for users.

The teacher use of shown in Figure 5 depicts

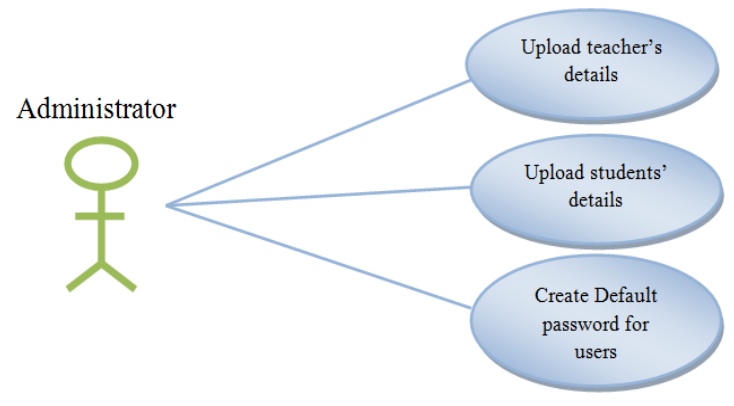

diagram as the process

Figure 4: CBT Diagram for Administrator 
of setting examination instruction, insertion of questions into database, insertion of options as well as the specification of correct answer(s) to question(s).

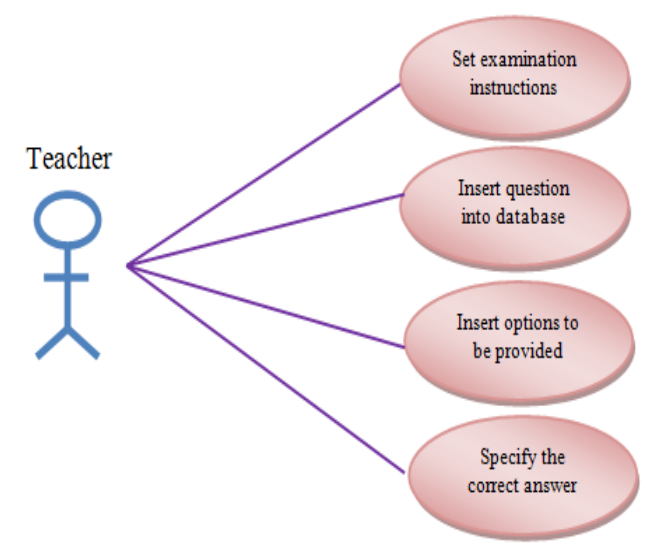

Figure 5: CBT Diagram for Teacher

The server use of diagram represents the responsibility of authenticating users of the system and providing timer functions for the examination are carried out. This is presented in Figure 6.

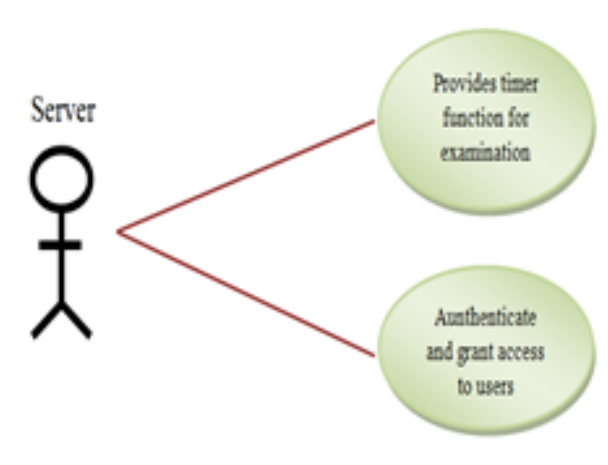

Figure 6: CBT Diagram for the CBT Server

The use of diagram for student shows that student can access the system and take their examination. Figure 7 presents the use of diagram for the student.

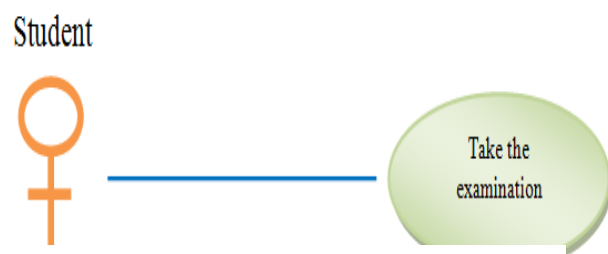

Figure 7: CBT Diagram for Student 


\subsubsection{Programming Tools}

To make the CBT system based on moodle had some stage proccess such as installation the web server xampp and moodle application initially. The component that needed to install xampp and moodle for the localhost need the spesification such as:

(a) Hardware inside 2 components with specification:
1) Hardisk
2) Memory

(b) Software within 4 components

1) $\mathrm{SO}$ windows XP7

2) Web server apache atau IIS

3) PHP (minimum versi 5.3.2)

4) Database include 5 program

- MySQL, version 5.0.25

- $\quad$ PostgreSQL, version 8.3

- MSSQL, version 9.0

- Oracle, version 10.2

- $\quad$ SQLite, version 2.0

\section{Results}

CBT system is composed of 6 different functional pages including the student login page, the admin login page, the question page, question upload and configuration page as well as the student result page.

\subsection{The Student Log In Page}

This is the default page of the system. It is also known as the homepage of the system that automatically loads after the URL has been requested for by a web browser on the client system. It contains the $\log$ in section for the student to provide their details which is used to authenticate the student to gain access to the system. This page is depicted in Figure 8 . The student logs-in with the matriculation number and password. The page also contains a link to the teacher login section.

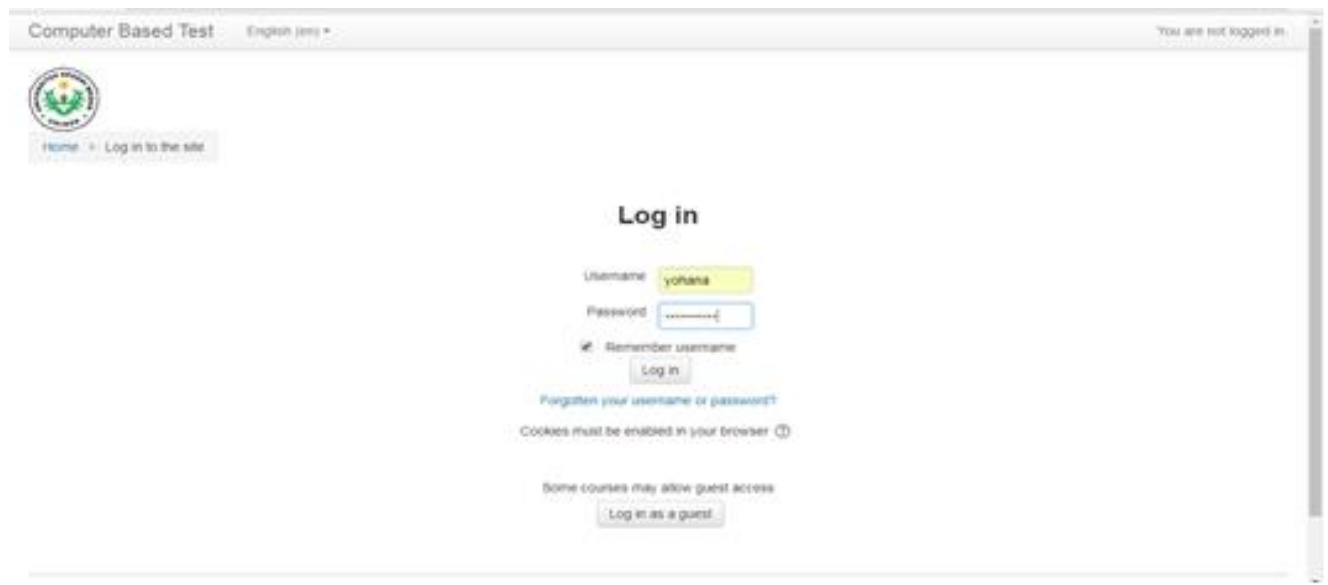

Figure 8: Students Login Page 


\subsection{The Admin Login Page}

As shown in Figure 9, this page is used by the teacher to log in into the CBT in other to carry out operations like setting question, viewing the result summary report to generate a complete list of student's grade after their examinations among other things. The teacher always $\log s$ in when the students logs-in

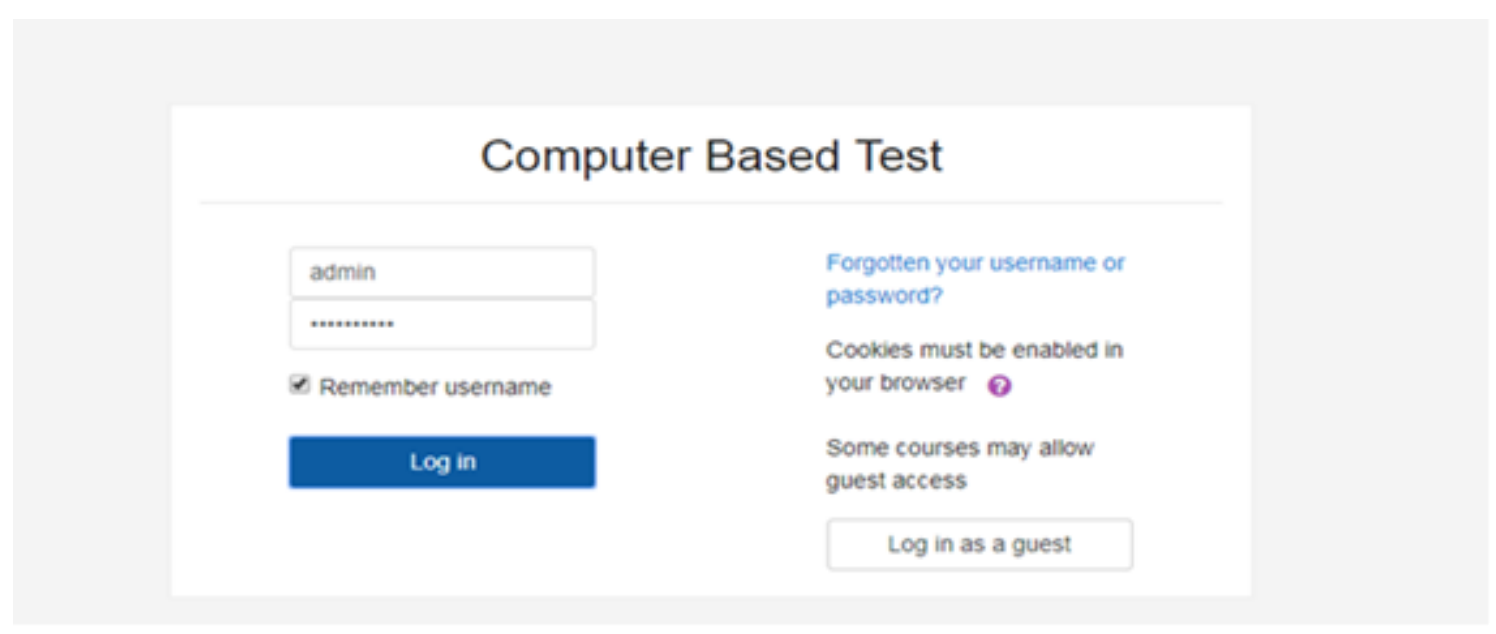

Figure 9: Admin Login Page

\subsection{The Question Page}

The page is used to serve the questions of the examination to the student. The page is depicted in Figure 10. The page upon load fetches questions from the database randomly and serves it to the student and the correct answer will be represents after the students submit all the answers and click the submit button. The correct answer in the students's option or present the answer in the required format required. The page also initiates a count-down timer which is used to manage the duration of the examination. 


\section{INSTRUMEN TES UJIAN NASIONAL}

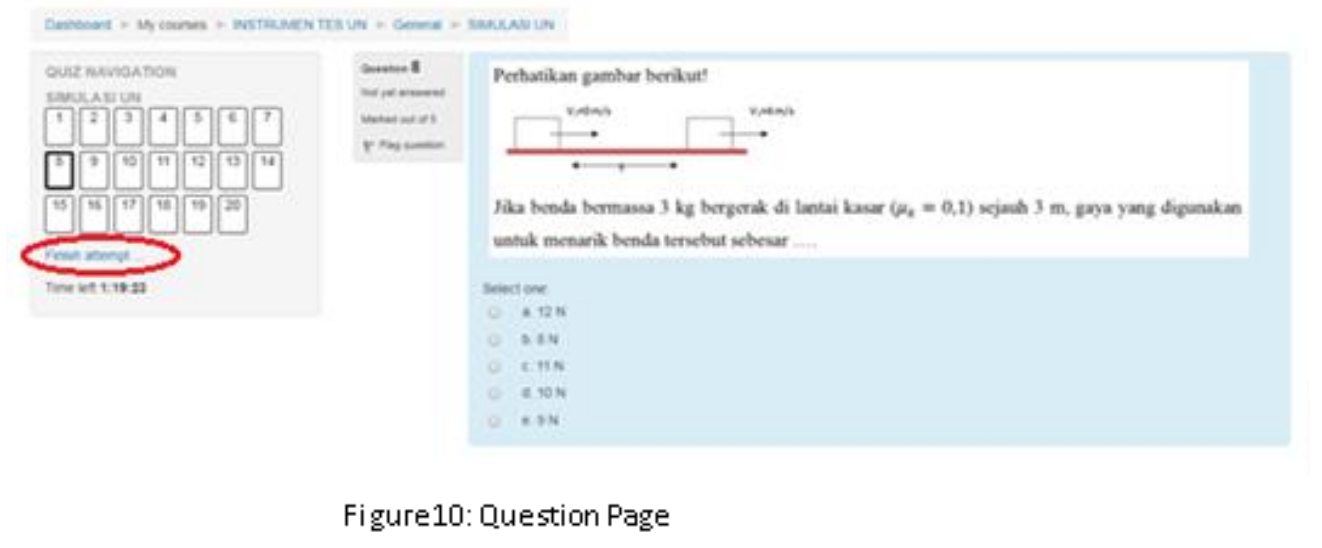

\subsection{Student Result Page}

The student result page is presented in Figure 11. This module is used to diplay the result of the student in the concluded examination, the result is computed based on the number of option sepecified by the teacher or answered in a preferred format presented by the teacher. The grade of the student is also displayed.

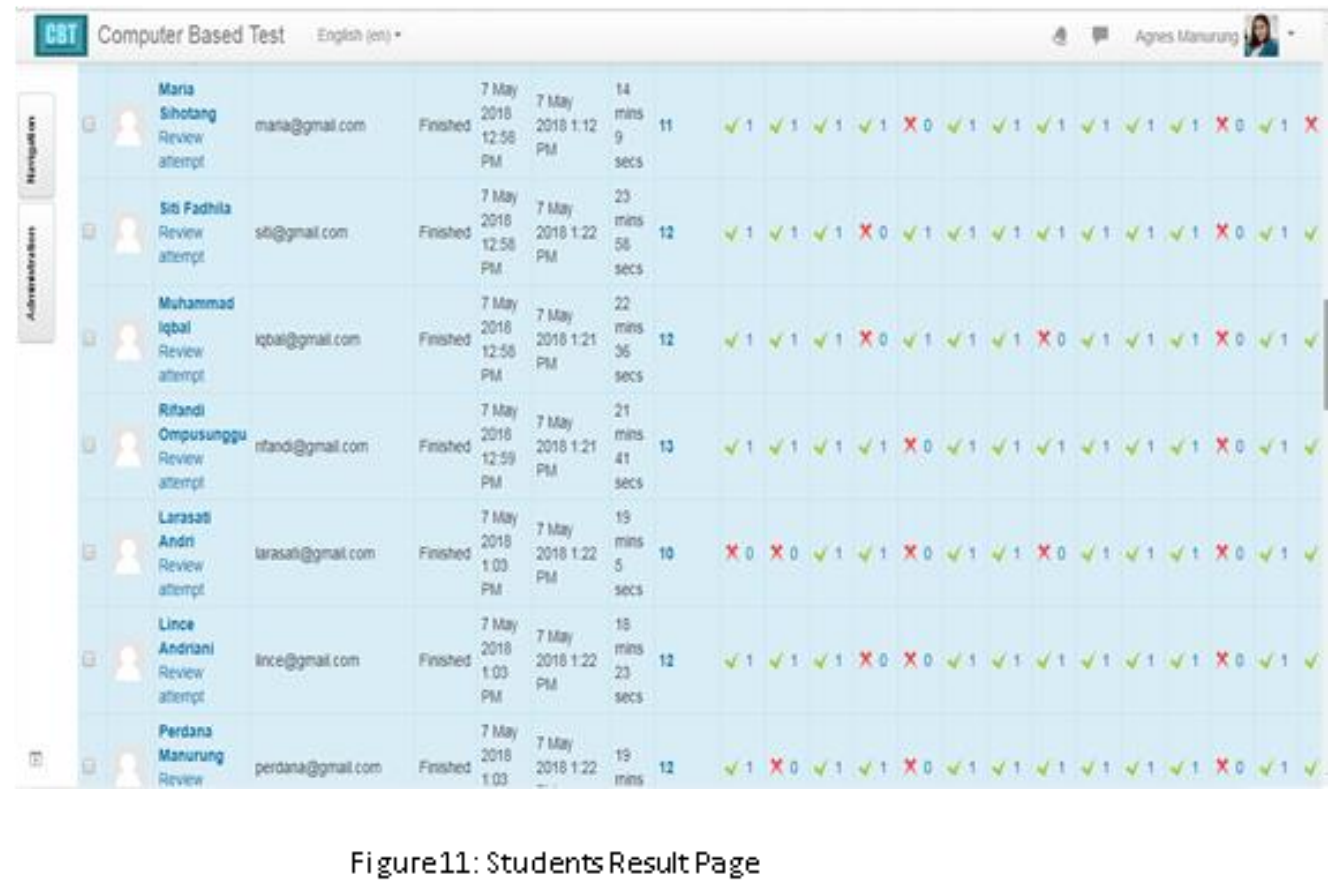




\subsection{Question Upload}

The page provides a platform for the teachers to input their question into database, while inputting the question into database, the teacher also has to specify the answer to the question. This page is displayed in Figure 12.

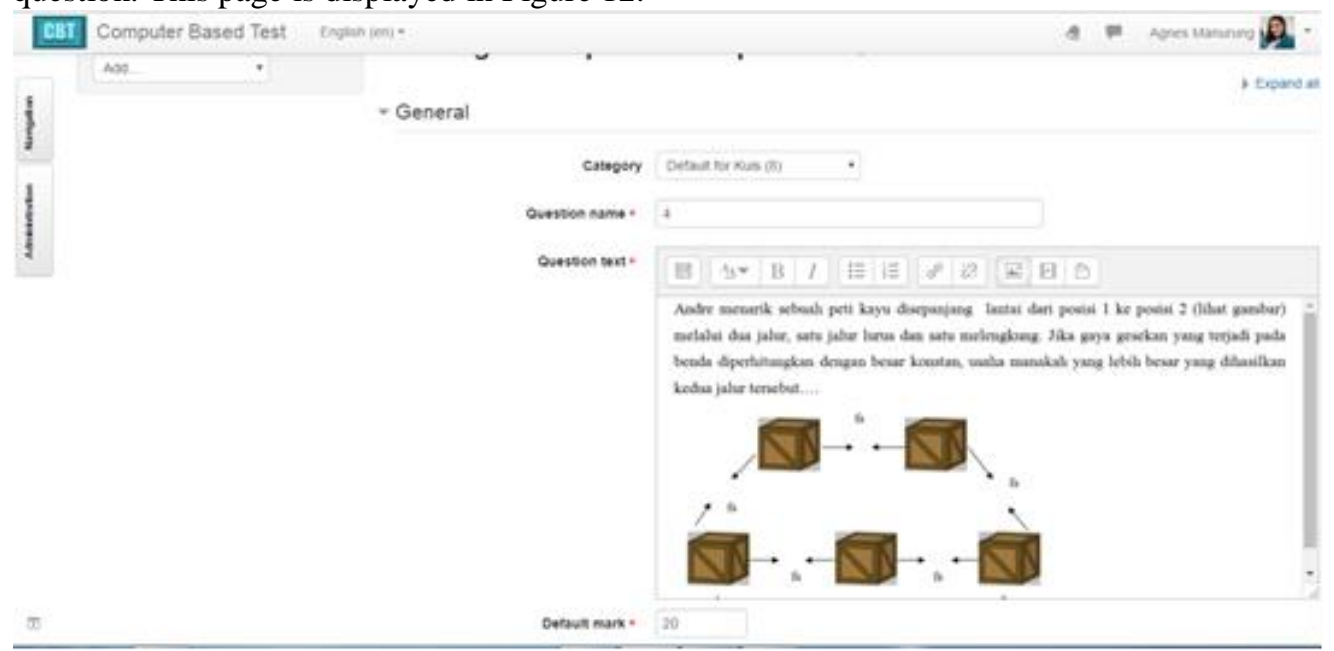

Figure 12: Question Upload and Configuration Page

\subsection{User Quality Assurance/ Performance Scoring of CBT Sytsem}

The user quality assurance and performance scoring test was carried out using evaluation metrics including user friendliness (tool-tip text, soft guide notes, pop-up messages), user interface design, realiabilty, robustness, ease of use, flexibilty (costumizable features/ control to suit the user's needs) and scability to incoporate new and advanced features. Performance assessment was carried out by 36 users of the CBT system and the average performance scoring is summarized in Figure 13.

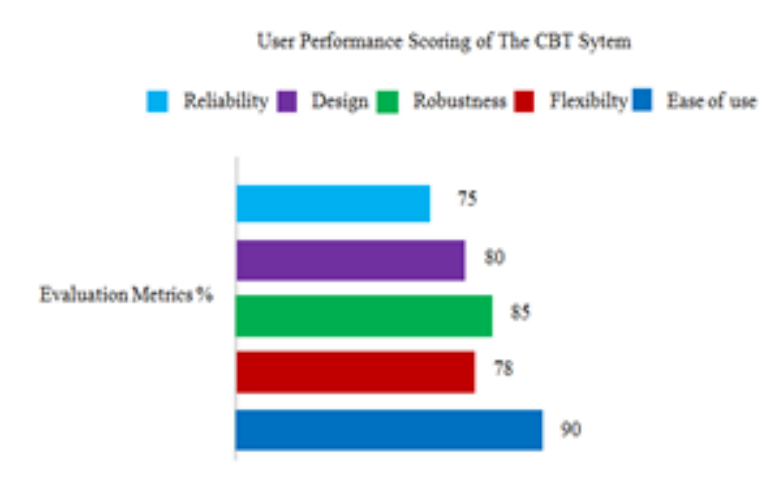




\section{Conclusions}

In this paper, a CBT is developed and proposed for students. The information system is an online examination system that delivers question by the teacher to the student and generates the report of the results of students who take the examination as well as overall examination result summary based on the user's account. Challenges including examination malpracties, low capacity examination venues, inadequate invigilators, inadequate examination materials, omission of student's results and human error(s) during the marking/grading process will be automatically elimanated following the adoption of this eexamination. However, future research work should accomodate theory-based questions as opposed to only that the CBT system currently accommodates. Also, provision for videobased e-assessment can be investigated.

\section{References}

[1]Akdemir, O., Oguz, A., 2008. Computer-based testing: An alternative for the assessment of Turkish undergarduate students. Computers \& Education. 51(3):1198-1204

[2]Al-Qdah, M., Ababneh, I., 2017. Comparing Online and Paper Exams: Performances and Perceptions of Saudi Students. International Journal of Information and Education Technology. 7(2): 106

[3]Al-Saleem, Saleh, M., 2016. A Comperehensive Analysis and Evaluation of Computer-based Testing Tools. Indian Journal of Science and Technology. 9(28)

[4]Arachchi, S., Dias., K., Madanayake, RS., Gunawardana, K., 2014. A comparison between Evaluation of computer based testing and paper based testing for subjects in Computer Programming. International Journal of Software Engineering \& Applications (IJSEA). 5(1)

[5]Hurley, A. 2017. Exlporing the Use of Computer Based Exams for Undergraduate Accounting. Irish Journal of Academic Practice. 6(1):8

[6]Kuyoro, S.O., Maminor, G.U., Kanu, R.U., \& Akande, O. 2016. The Design and Implementation of a Computer Based Testing System. Journal of Applied Computation. 01(01)

[7]Piech, C., \& Gregg, C. 2018. BlueBook: A Computerized Replacement for Paper Tests in Computer Science. In SIGCSE'18: SIGCSE'18: The $49^{\text {th }}$ ACM Technical Symposium on Computer Science Education.

[8]Shilova, TV., Artamonova, LV., Averina, SY., 2014. Computer-based Tests as an Integral Component of an EFL Course in Moodle for Non-linguistic Students. Procedia-Social and Behavioral Sciences. 154: 434-436

[9]Singh, SK., Tiwari, AK., 2016. Design and implementation of secure computer based examination system based on b/s structure. International Journal of Applied Engineering Research. 11(1): 312-318 [10]Thurlow, M., Lazarus, S.S., Albus, D., \& Hodgson, J. 2010. Computer-based testing: Practices and considerations (Synthesis Report 78). Minneapolis, MN: University of Minnesota, National Center on Educational Outcomes. 